\title{
Austenite Grain Refining of As-cast Bloom Surface by Reduction of Oscillation Mark Depth
}

\author{
Yasuhide OHBA, ${ }^{1)}$ Shin-ichi KITADE ${ }^{2)}$ and Ichiro TAKASU ${ }^{11}$ \\ 1) Process Development Group, Research \& Development Center, Sanyo Special Steel Co., Ltd., 3007, Nakashima, Shikama- \\ ku, Himeji 672-8677 Japan. $\quad$ 2) Steelmaking Technology Group, Steelmaking Department, Sanyo Special Steel Co., Ltd., \\ 3007, Nakashima, Shikama-ku, Himeji 672-8677 Japan.
}

(Received on July 30, 2007; accepted on January 11, 2008)

\begin{abstract}
Austenite grain refining in the surface layer of as-cast bloom is effective for the reduction of surface cracks in steel production. This study was carried out to clarify the influence of cooling rate on the as-cast austenite grain size and its growth mechanism. Depth and interval of oscillation marks were reduced and the austenite grains at the bloom surface were refined under the oscillation conditions of shorter stroke and higher frequency. The average cooling rates were estimated to be from 6 to $16 \mathrm{~K} / \mathrm{s}$ in austenite phase temperature and the rates were related to characteristics of oscillation mark. It was found that the austenite grain growth direction did not vary even when characteristics of oscillation mark changed. The austenite grain size below the surface layer was also determined by austenite grain size at the bloom surface.
\end{abstract}

KEY WORDS: austenite grain; grain size; refining; grain growing; continuous casting; oscillation mark; cooling rate; as-cast.

\section{Introduction}

Surface cracks on continuously cast blooms are sometimes generated by tensile stress and strain. Since surface cracks are generated and propagated along the austenite $(\gamma)$ grain boundary at the $\gamma$ phase temperature region, it is important to refine $\gamma$ grain on as-cast bloom surface for prevention of surface cracks. ${ }^{1)}$ During continuous casting, oscillation marks (OSM) are formed on the bloom surface. The $\gamma$ grain at the bottom of OSM where the cooling rate is lower than the top of OSM tends to be coarse. ${ }^{1,2)}$ Surface cracks on the bloom surface tend to occur at the bottom of OSM. This tendency is considered to be due to not only the notch effect of $\mathrm{OSM}^{3,4)}$ but also coarse $\gamma$ grain. Higher cooling rate $^{5)}$ and the use of non-metallic inclusions ${ }^{6)}$ are refining methods for $\gamma$ grain. Since non-metallic inclusions may deteriorate the characteristics of products, higher cooling rate by reducing the OSM depth was employed for the reduction of $\gamma$ grain size. In this paper, continuous casting tests under the oscillation conditions of shorter stroke and higher frequency were conducted to reduce the OSM depth. ${ }^{7)}$ Influence of the cooling rate on the as-cast $\gamma$ grain size and the growth mechanism of the $\gamma$ grain were examined.

\section{Experimental Procedure}

The chemical compositions of the bloom specimens, which are case-hardening steel of 0.20 mass $\%$ carbon, are shown in Table 1. The casting conditions are shown in Table 2. Sinusoidal curve was adopted for mold oscillation mode. Five oscillation conditions with different strokes and different negative strip ratios were examined by using the

Table 1. Chemical compositions of the specimen (mass $\%$ ).

\begin{tabular}{cccccc}
\hline $\mathrm{C}$ & $\mathrm{Si}$ & $\mathrm{Mn}$ & $\mathrm{P}$ & $\mathrm{S}$ & $\mathrm{Cr}$ \\
\hline 0.20 & 0.30 & 0.83 & 0.017 & 0.017 & 1.18 \\
\hline
\end{tabular}

Table 2. Casting conditions.

\begin{tabular}{cccccc}
\hline Condition & (1) & (2) & (3) & (4) & (5) \\
\hline Bloom dimension $[\mathrm{mm} \times \mathrm{mm}]$ & & $380 \times 490$ & & \\
Casting velocity [m/min] & & 0.5 & & \\
Superheat [K] & 4 & 4 & 2.6 & 2 & 2 \\
\hline Oscillation stroke [mm] & 104 & 129 & 160 & 135 & 208 \\
Oscillation frequency [cpm] & 75 & 80 & 75 & 60 & 75 \\
Negative strip ratio [\%] & 0.22 & 0.19 & 0.14 & 0.13 & 0.11 \\
Negative strip time [s] & & & 0.6 & & \\
\hline Mold powder CaO/SiO 2 & & 2.4 & & \\
Mold powder viscosity at $1573 \mathrm{~K}[\mathrm{~Pa} \cdot \mathrm{s}]$ & & & &
\end{tabular}


commercial production process. The super heats for specimen were $25 \mathrm{~K}$, and their casting speeds were $0.5 \mathrm{~m} / \mathrm{min}$. The mold power used for casting has 0.6 in basicity and $2.4 \mathrm{~Pa} \cdot \mathrm{s}$ in viscosity at $1573 \mathrm{~K}$. Oscillation conditions became shorter in stroke and higher in frequency by order of condition 1 to 5 . The strokes in conditions 1 and 2, 4 and 5 were the same, while the negative strip ratio in conditions 1 , 3 and 5 were the same.

The steel specimens were prepared through the following procedure. An as-cast bloom was collected per one condition and four specimens were cut out $25 \mathrm{~mm}$ along the casting direction from its quarter in width on a narrow side of each bloom. Each specimen was mounted, polished and etched by picric acid for the observation of the dendritic structures and by $5 \% \mathrm{HNO}_{3}$ for the observation of the former $\gamma$ grain boundary. The surface layer structure of the specimens was examined by optical microscope. Thus, measurements of the OSM depth and the $\gamma$ grain size of the bloom were defined as the mean value in $100 \mathrm{~mm}$ that was the total length of four specimens. Figure 1 shows an example of specimens. The specimen is approximately $25 \mathrm{~mm}$ long, and contains 5-10 marks on it. The OSM depths were defined as the distance between the bottom of the OSM and the tangent line of the 2 neighbor tops of the OSM. Grains in surface layer were columnar shape. The minor axis of $\gamma$ grain was taken as an as-cast $\gamma$ grain size. The as-cast $\gamma$ grain size at each distance from bloom surface was taken from the number of grain boundary crossed the $100 \mathrm{~mm}$ as Esaka et al. did. $\left.{ }^{8}\right)$ The cooling rate during the solidification was estimated by using the Eq. (1). ${ }^{9)}$

$$
S=710 R_{\mathrm{LS}}^{-0.39}
$$

Where, $S$ is secondary dendrite arm spacing, and $R_{\mathrm{LS}}$ is the average cooling rate during solidification. $R_{\mathrm{LS}}$ at the top and bottom of OSM was estimated by measuring the secondary dendrite arm spacing there respectively.

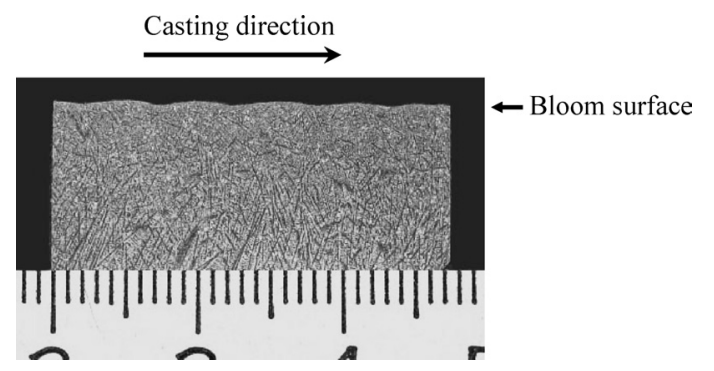

Fig. 1. Appearance of a specimen at the cross section of the oscillation marks (an example).

\section{Results}

Figure 2 shows appearances of bloom surfaces in the conditions 1, 3 and 5. Bloom surface in the condition 1, 3, 5 were called as bloom 1, 3, 5 respectively. Both the intervals and the depths of OSM have reduced in the order of condition 1 to 5 . The OSM in the condition 5 was hardly observed. The OSMs of blooms 1 and 3 were formed straightly with equal interval. These results suggested that blooms were cast in a stable condition without any troubles, such as inconsistent infiltration of slag at meniscus, the misfit of the mold oscillation and the movement of initially solidified shell. ${ }^{10)}$

Figure 3 shows relationship between the negative strip time $^{11)}$ and the OSM depth. Average OSM depth was reduced with oscillation conditions of shorter stroke and higher frequency. ${ }^{3,11-13)}$ There is small difference in mold powder consumption among conditions although the OSM characteristics were different. In general, sticking of the solidified shell and the mold could occur due to lack of slag infiltration. ${ }^{14)}$ There was no sign of the sticking and surface cracks. These results suggested that the slag infiltration was stable and uniform in these tests.

Figure 4 shows micrographs of austenite grains at the cross section of oscillation marks. The $\gamma$ grain morphology of as-cast bloom was columnar and growing toward inside. The results showed that the temperature gradient at the growth edge of $\gamma$ grains was large. ${ }^{15)}$ The $\gamma$ grains were refined, both at the bottom of OSM and at the top of OSM under the condition of shorter stroke and higher frequency. This tendency would be due to the uniformity of cooling rate between the bottom and the top of the OSM. This uniformity was related to not only the OSM depths but also the OSM intervals. ${ }^{2}$ )

Figure 5 shows relationship between OSM depths and $\gamma$ grain sizes at various distances from surface. Where, the value of OSM depths and $\gamma$ grain sizes shown in Fig. 5 were the average value by each $25 \mathrm{~mm}$ long specimen

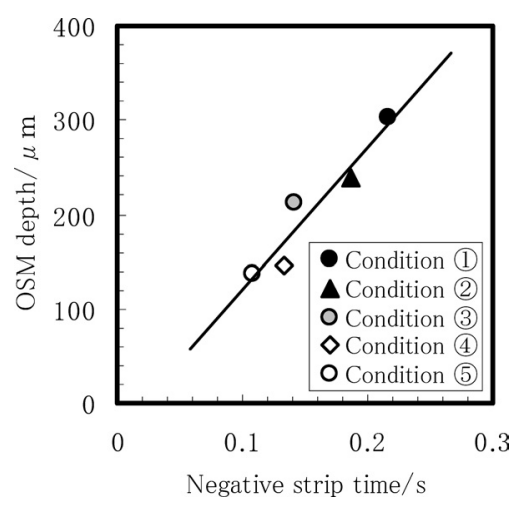

Fig. 3. Relationship between negative strip time and OSM depth.
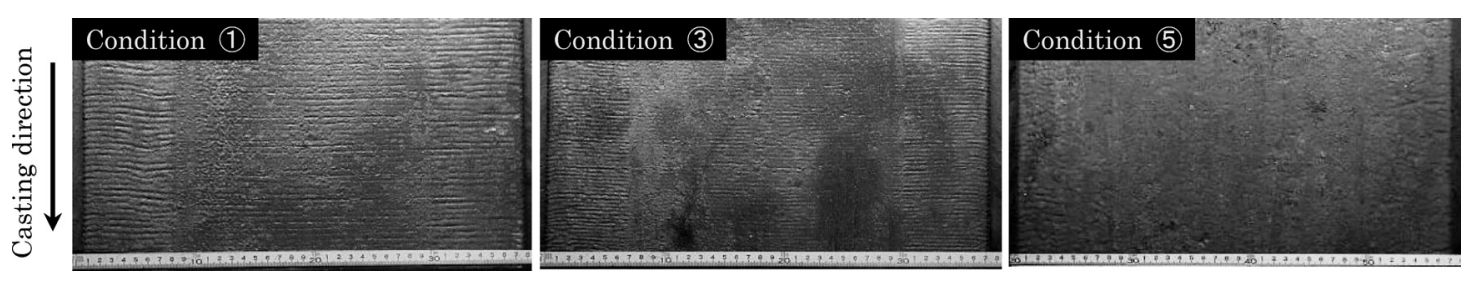

Fig. 2. Appearance of bloom surface. 


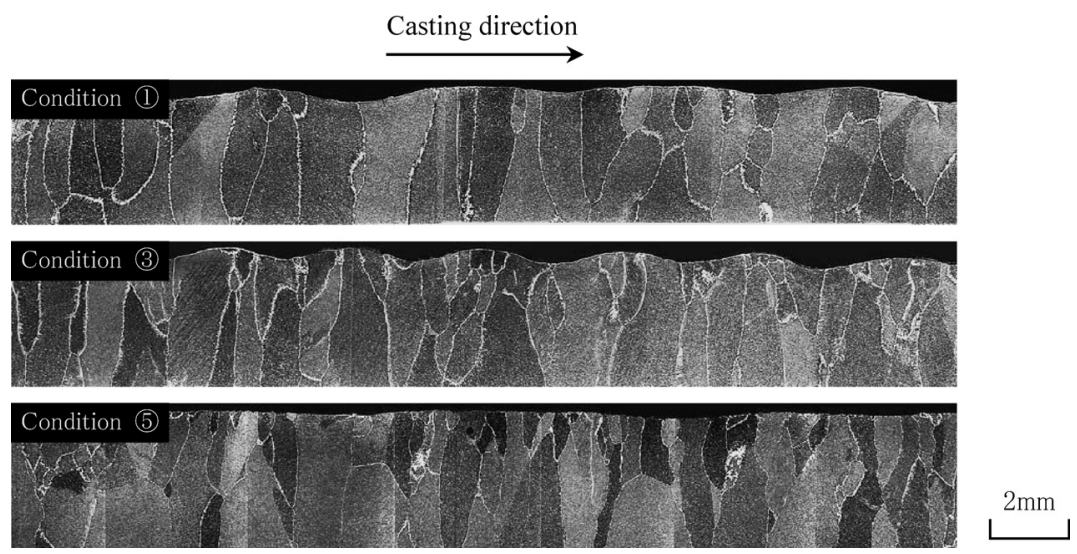

Fig. 4. Micrographs of austenite grains at the cross section of oscillation marks.

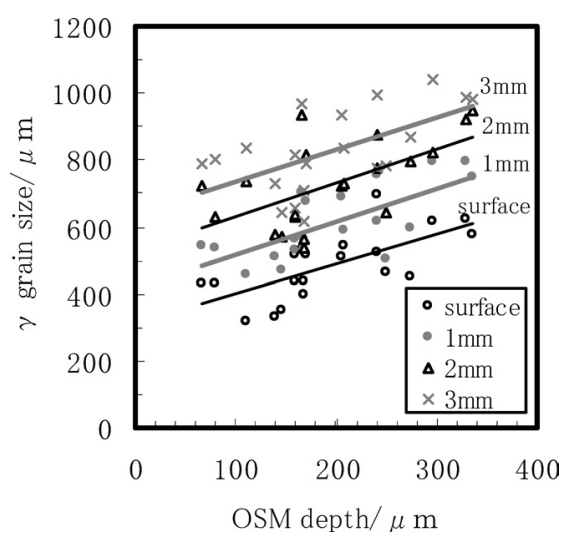

Fig. 5. Relationship between OSM depth and austenite grain size at different depth from surface.

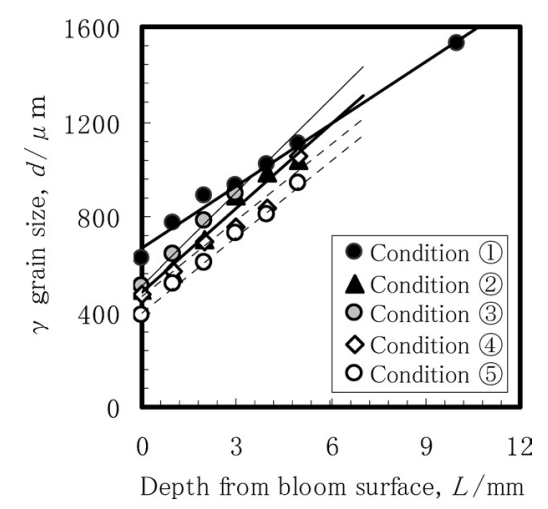

Fig. 6. Relationship between depth from bloom surface and austenite grain size for different oscillation conditions.

respectively, and all measurements for condition 1 through 5 were shown in Fig. 5. $\gamma$ grains from the surface to $3 \mathrm{~mm}$ depth were refined with reducing OSM depth. Consequently, $\gamma$ grain sizes were related to OSM depths even when mold oscillation conditions changed.

Figure 6 shows relationship between the depth from bloom surface and the average $\gamma$ grain size for each oscillation conditions. $\gamma$ grains were refined under the oscillation conditions of shorter stroke and higher frequency. $\gamma$ grain was the smallest at the surface, and average $\gamma$ grain size linearly increase with the depth from the bloom surface. The approximation straight lines of the relation between $d$ and $L$ of conditions 1 through 5 were shown in Fig. 6. It was thought that slopes of the straight lines were almost same though it would describe in Fig. 8 later.

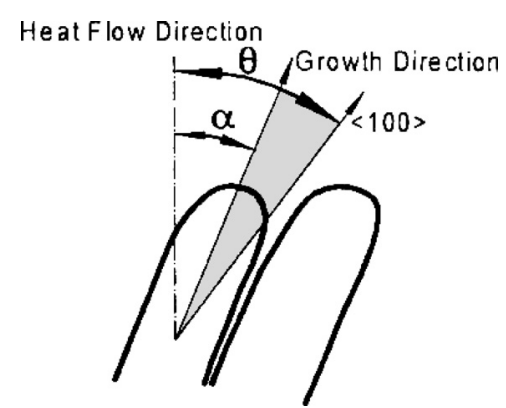

Fig. 7. Relation among $\langle 100\rangle$, growth direction and heat flow direction.

\section{Discussion}

Cooling rate, grain selection behavior, inclusion, and steel composition can be factors that influence the $\gamma$ grain size. In this experiment, there was no significant difference in the steel compositions and the inclusion levels. Therefore, the $\gamma$ grain size was examined from the viewpoint of the grain selection behavior and the cooling rate. Esaka et al. ${ }^{16,17)}$ have reported the relation between the normalized number of grains $\left(n / n_{0}\right)$, where $n$ is the number of grains, $n_{0}$ is the initial number of grains, and the normalized growth length $\left(L / d_{0}\right)$, where $L$ is the growth length, $d_{0}$ is the initial grain size, by using the grain selection model. Esaka et al. said that $n / n_{0}$ decreased with $L / d_{0}$, and the grain selection behavior changed from heat flow direction $\left(\pi^{\prime}=0\right)$ to prioritized growth direction $\left(\pi^{\prime}=1\right)$ by introducing the growth direction parameter $\pi^{\prime},{ }^{16)}$ which showed the direction of the $\gamma$ grain growth. Figure $7^{16)}$ shows the relation among $\langle 100\rangle$, growth direction and heat flow direction. The growth of the crystal whose priority growth direction shifts only $\theta$ from heat flow direction follows $\alpha$ shifted from the heat flow direction, that is, the direction of $\pi^{\prime} \cdot \theta . \pi^{\prime}$ takes the value between $0-1$ under such assumption. Figure 8 shows the relation between the normalized grain sizes $\left(d / d_{0}\right)$ and $L / d_{0}$, where $d$ is the $\gamma$ grain size and $L$ is the depth from the bloom surface shown in Fig. 6 . Each average $\gamma$ grain size at the surface of the blooms 1 through 5 were applied to $d_{0}$, respectively. Since the reciprocal of $n / n_{0}$ was $d / d_{0}$, the relation between $L / d_{0}$ and $n / n_{0}$ shown by Esaka et al., ${ }^{16)}$ can be converted into it between $L / d_{0}$ and $d / d_{0}$. The relation between $L / d_{0}$ and $d / d_{0}$ for $\pi^{\prime}=0-1$ was approximately linear, respectively. The approximated straight lines for $\pi^{\prime}=0-1$ were shown in Fig. 8. Most of the average $\gamma$ grain sizes for 


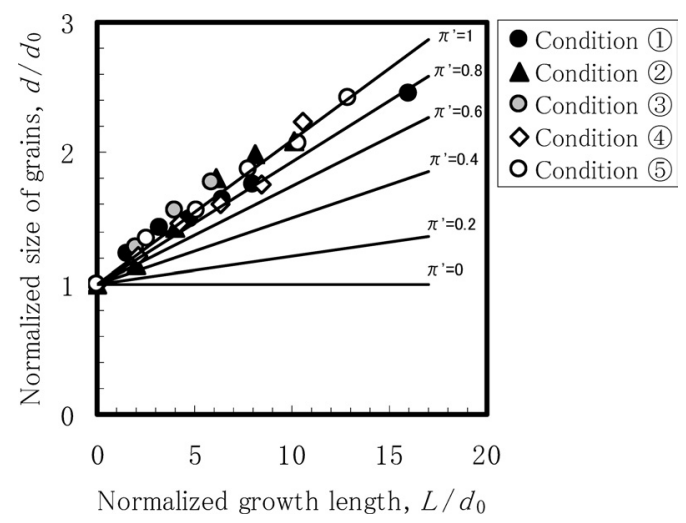

Fig. 8. Relationship between normalized size of grains and normalized growth length.

the blooms 1 through 5 were found to be around the approximated straight line for $\pi^{\prime}=1$, that is, the direction of the prioritized $\gamma$ grain growth. Regarding the $\gamma$ grain growth direction, $\pi^{\prime}=1$ and $\pi^{\prime}=0$ correspond to the priority growth direction and the heat flow direction, respectively. Therefore, it indicates that the smaller value of $\pi^{\prime}$ corresponds to larger heat extraction from the initial solidification shell to copper mold. The refinement of the $\gamma$ grain under the oscillation conditions of shorter stroke and higher frequency was considered to be due to the intensified cooling of the initial solidification shell. However, from the viewpoint of the grain selection, there was no influence of the heat flow direction and no change in the $\gamma$ grain growth direction.

Influence of the cooling rate during solidification $\left(R_{\mathrm{LS}}\right)$, and of the average cooling rate in the $\gamma$ phase temperature region $\left(R_{\gamma}\right)$ and solidification rate $(V)$ on the $\gamma$ grain size were investigated. $R_{\mathrm{LS}}$ at $2 \mathrm{~mm}$ inside from the bloom surface is shown in Fig. 9. By the secondary dendrite arm spacing, the cooling rates at the top and the bottom of OSM were estimated to from 18 to $27 \mathrm{~K} / \mathrm{s}$, and from 7 to $18 \mathrm{~K} / \mathrm{s}$, respectively. The cooling rates at the bottom of the OSM for all of the blooms 1 through 5 were found to be lower than those at the top of OSM for $10 \mathrm{~K} / \mathrm{s}$. Moreover, regarding the bloom 5 , the cooling rates not only at the bottom of OSM but also at the top were higher for $10 \mathrm{~K} / \mathrm{s}$ than those of bloom 1. It is because the reduction of the OSM depth and its interval would reduce the influence of the delayed solidification at the bottom of $\mathrm{OSM}^{2)}$ and the heat transfer in the casting direction from the bottom of OSM to the top.

Yoshida et al. ${ }^{18)}$ derived the relational equation of $\mathrm{R}_{\gamma}$ and casting $\gamma$ grain diameter $(d)$ from the casting experiment with 0.1 mass $\% \mathrm{C}$ steel and the theoretic calculation of the grain growth (Eq. (2)).

$$
d=1.52 R_{\gamma}{ }^{-0.5}
$$

Figure 10 shows the relation between the depth from the bloom surface and $R_{\gamma}$, which was calculated by the average $\gamma$ grain size shown in Fig. 6 , referring the Eq. (2). ${ }^{18)} \mathrm{Re}-$ garding $R_{\gamma}$ at the surface of the bloom, $6 \mathrm{~K} / \mathrm{s}$ for the bloom $1,9.5$ to $11 \mathrm{~K} / \mathrm{s}$ for the blooms 2 through 4 , and $16 \mathrm{~K} / \mathrm{s}$ for the bloom 5 were obtained. This cooling rate tendency would be due to the reduction of the OSM depth. Regarding the blooms 2 through 4 , their $R_{\gamma}$ were not so different

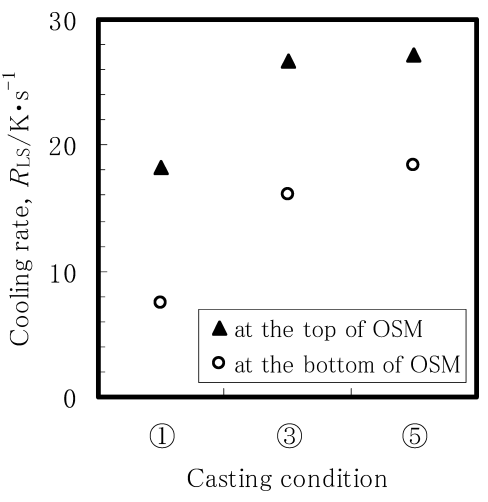

Fig. 9. Relationship between casting condition and cooling rate at the position of $2 \mathrm{~mm}$ inside from the surface.

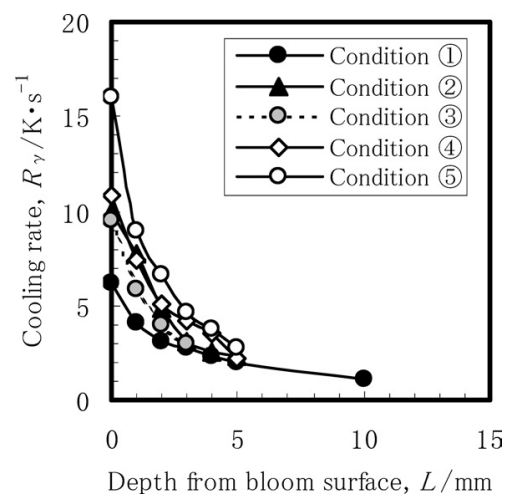

Fig. 10. Relationship between depth from bloom surface and cooling rate.

though the OSM depth had different values. It is also because of the influence of the OSM intervals as mentioned above. Specifically speaking, there was no significant difference in the OSM depth between the blooms 2 and 3, and bloom 4 had larger OSM interval and smaller OSM depth than bloom 3. Consequently the $R_{\gamma}$ for the blooms 2 and 4 would not be much different from that for the bloom 3. $R_{\gamma}$ decreased rapidly with the depth from the bloom surface, and the $R_{\gamma}$ of from 2 to $3 \mathrm{~K} / \mathrm{s}$ at $5 \mathrm{~mm}$ depth and $1 \mathrm{~K} / \mathrm{s}$ at $10 \mathrm{~mm}$ depth were obtained. $R_{\gamma}$ at $2 \mathrm{~mm}$ depth was $7 \mathrm{~K} / \mathrm{s}$ for the bloom 5 and $3 \mathrm{~K} / \mathrm{s}$ for the bloom 1 . In this way, the cooling rate at the $2 \mathrm{~mm}$ depth from the surface rose by shorter stroke and higher frequency, and $R_{\mathrm{LS}}$ and $R_{\gamma}$ were increased by $10 \mathrm{~K} / \mathrm{s}$ and $4 \mathrm{~K} / \mathrm{s}$, respectively. Therefore, when $\gamma$ grain refinement for the bloom 5 was caused by the raised $R_{\gamma}, R_{\gamma}$ values from the bloom surface to $5 \mathrm{~mm}$ depth for the bloom 5 were from 1.5 to 2.5 times as high as those for the bloom 1 .

The relation between $V$ and the average $\gamma$ grain size was examined as follows. To estimate $V$ of each depth from the surface in bloom 1, sulfur was added into the mold at the continuous caster, ${ }^{19)}$ and the initial solidification shell thickness was measured by the sulfur-print at the cross section of the bloom. The approximated equation of $D=\mathrm{k} t^{\mathrm{x}}$ was obtained between the passage time $(t)$ from the meniscus and the shell thickness measured $(D)$, where $\mathrm{k}$ and $\mathrm{x}$ are constants. Solidification rate $V_{t}$ at $t$ was estimated by differentiating the $D$ by $t$. Figure 11 shows the relation between the obtained $V$ and the $\gamma$ grain size of bloom 1 shown in Fig. 6 . Maruyama et $a .^{20,21)}$ have reported the relation between $V$ 


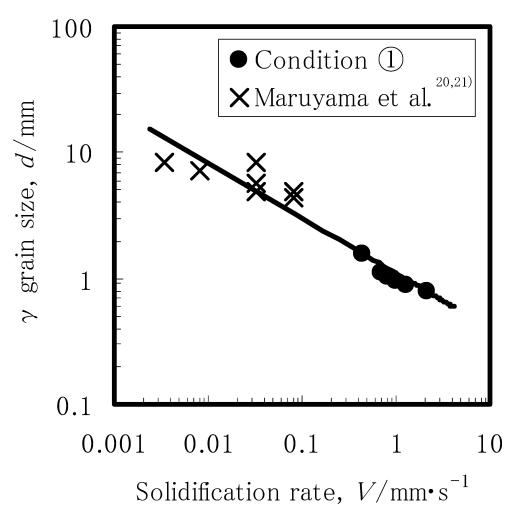

Fig. 11. Relationship between austenite grain size and solidification rate.

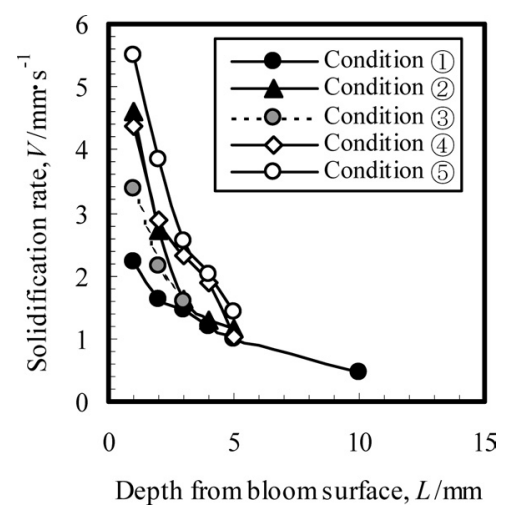

Fig. 12. Relationship between depth from bloom surface and solidification rate.

and the cast $\gamma$ grain size in hypo- and hyper-peritectic carbon steel as shown in the figure. Solidification rate for the bloom 1 was 100 times larger and the casting $\gamma$ grain size was one-tenth compare with Maruyama et al.'s results. It can be considered that relationship between $V$ and $d$ on bloom 1 showed same tendency as those of Maruyama et al.'s. When the relation between $V$ and $d$ shown in Fig. 11 is approximated by the Eq. (3).

$$
d=1.10 \mathrm{~V}^{-0.44}
$$

Figure 12 shows the relation between the depth from the bloom surface and $V$, which was calculated by the average $\gamma$ grain size shown in Fig. 6, referring the Eq. (3). Therefore, when $\gamma$ grain refinement for the bloom 5 was caused by the raised $V$, solidification rate from the bloom surface to $5 \mathrm{~mm}$ depth for the bloom 5 were 1.5 through 2.5 times larger than those for the bloom 1 .

Therefore, the refinement of $\gamma$ grains was considered to be due to the refinement of the initial $\gamma$ grain at the bloom surface. It was found that the initial $\gamma$ grain refinement was caused by the decreased solidification delay and the increased average cooling rate at the bloom surface due to the reduction of the OSM depths and intervals. In consequence of the prediction from $\gamma$ grain sizes, it could be estimated that both $R_{\gamma}$ and $V$ for bloom 5 were raised approximately 1.5 through 2.5 times of those for bloom 1 .

\section{Conclusions}

The continuous casting tests in the commercial produc- tion process were carried out under various oscillation conditions. The influence of the cooling rate on the $\gamma$ grain size and the growth mechanism of the $\gamma$ grain were studied with the following conclusions:

(1) Depths and intervals of the oscillation mark were reduced and the $\gamma$ grains were refined in the oscillation conditions of shorter stroke and higher frequency, whether at the bottom of OSM or at the top of it.

(2) The depth from the bloom surface and the average $\gamma$ grain size had a linear relationship.

(3) It was found that the austenite grain growth direction did not vary even when characteristics of the oscillation mark changed. The austenite grain size below the surface layer was also determined by austenite grain size at the bloom surface. Refinement of the initial $\gamma$ grain was due to higher average cooling rate, which was caused by smaller OSM depths and intervals.

(4) The average cooling rates were estimated to be from 6 to $16 \mathrm{~K} / \mathrm{s}$ in $\gamma$ phase temperature, depending on the characteristics of OSM.

(5) The relation between $V$ and $d$ was approximated by the equation of $d=1.10 \mathrm{~V}^{-0.44}$.

(6) It could be estimated that both $R_{\gamma}$ and $V$ at the bloom surface were raised by approximately 1.5 through 2.5 times by shorter stroke and higher frequency of the mold oscillation.

\section{REFERENCES}

1) Y. Maehara, K. Yasumoto, Y. Sugitani and K. Gunji: Tetsu-toHagané, 71 (1985), 1534.

2) E. Takeuchi and J. K. Brimacombe: Metall. Trans. B, 16B (1985), 605.

3) K. Kawakami, T. Kitagawa, H. Mizukami, H. Uchibori, S. Miyahara, M. Suzuki and Y. Shiratani: Tetsu-to-Hagané, 67 (1981), 1190.

4) Y. Maehara, H. Tomono and K. Yasumoto: Tetsu-to-Hagané, 74 (1988), 151.

5) K. Yasumoto, T. Nagamichi, Y. Maehara and K. Gunji: Tetsu-toHagané, 73 (1987), 1738.

6) H. Suito, H. Ohta and G. V. Pervushin: CAMP-ISIJ, 13 (2000), 752.

7) H. Takeuchi, S. Matsumura, R. Hidaka, Y. Nagano and Y. Suzuki: Tetsu-to-Hagané, 69 (1983), 248.

8) Y. Kuroda, H. Esaka, K. Shinozuka and M. Tamura: Tetsu-toHagané, 92 (2006), 432.

9) A. Suzuki, T. Suzuki, Y. Nagaoka and Y. Iwata: J. Jpn. Inst. Met., 32 (1968), 1301.

10) Y. Ohba, I. Takasu, S. Kitade and H. Shimoguchi: Tetsu-to-Hagané, 92 (2006), 439

11) T. Emi, H. Nakada, Y. Iida, K. Emoto, R. Tachibana, T. Imai and H. Bada: Steelmaking Conf. Proc., ISS-AIME, Warrendale, PA, (1978), 350 .

12) M. Wolf: Tetsu-to-Hagané, 67 (1981), S904.

13) H. Takeuchi, S. Matsumura and Y. Ikehara: Tetsu-to-Hagané, 69 (1983), 1995.

14) T. Okazaki, H. Tomono, K. Ozaki and H. Akabane: Tetsu-to-Hagané, 68 (1982), S929.

15) K. Matsuura, Y. Itoh and K. Matsubara: Tetsu-to-Hagané, 76 (1990), 714.

16) H. Esaka, K. Fujita, H. Daimon, M. Tamura and K. Shinozuka: J. Jpn. Inst. Met., 64 (2000), 1206.

17) H. Esaka, K. Shinozuka and M. Tamura: ISIJ Int., 43 (2003), 1751.

18) N. Yoshida, Y. Kobayashi and K. Nagai: Tetsu-to-Hagané, 90 (2004), 198.

19) T. Saeki, S. Ooguchi, S. Mizoguchi, T. Yamamoto, H. Misumi and A. Tsuneoka: Tetsu-to-Hagané, 68 (1982), 1773.

20) T. Maruyama, K. Matsuura, M. Kudoh and Y. Itoh: Tetsu-to-Hagané, 85 (1999), 585.

21) T. Maruyama, M. Kudoh and Y. Itoh: Tetsu-to-Hagané, 86 (2000), 86. 